Original Article

\title{
Comparison of the psychometric properties of two balance scales in children with cerebral palsy
}

\author{
Yong-Jin JeOn, PT, PhD ${ }^{1)}$, Gyoung-Mo KIm, PT, PhD )** $^{*}$ \\ 1) Department of Physical Therapy, School of Medical and Public Health, Kyungdong University, \\ Republic of Korea \\ 2) Department of Physical Therapy, Division of Health Science, Baekseok University: 76 Munam-ro, \\ Dongnam-Gu, Cheonan, Chungnam 330-704, Republic of Korea
}

\begin{abstract}
Purpose] The purpose of this study was to compare the item difficulty degree between the Pediatric Balance Scale and Fullerton Advanced Balance scale for children with cerebral palsy. [Subjects and Methods] Forty children with cerebral palsy (male $=17$, female $=23$ ) voluntarily participated in the study. Item difficulty was expressed in the Rasch analysis using a logit value, with a higher value indicative of increasing item difficulty. [Results] Among the 24 items of the combined Pediatric Balance Scale and Fullerton Advanced Balance scale, the most difficult item was "Walk with head turns", whereas, the easiest item was "Sitting with back unsupported and feet supported on the floor". Among the 14 items of the Pediatric Balance Scale, 9 items (item 1, 2, 3, 4, 5, 6, 7, 11, and 12) had negative logit values, whereas for the Fullerton Advanced Balance scale, only 1 item (item 1) had a negative logit value. [Conclusion] The Fullerton Advanced Balance scale is a more appropriate tool to assess balance ability than the Pediatric Balance Scale in in a group of higher functioning children with cerebral palsy.

Key words: Balance, Cerebral palsy, Rasch analysis
\end{abstract}

(This article was submitted Aug. 4, 2016, and was accepted Aug. 23, 2016)

\section{INTRODUCTION}

Cerebral palsy (CP) is defined as a permanent neurological disorder caused by a non-progressive brain injury or damage to the brain ${ }^{1)}$. CP primarily affects muscle tone, coordination, control movement, and balance ${ }^{1,2)}$. Many children with CP have neuromuscular deficits, including the lack of motor control, abnormal muscle tone, impaired coordination, sensory problems, and impaired balance control. Balance control is imperative to all movements, and a major factor restricting functional ability is poor balance control ${ }^{2}$. Thus, a reliable and valid assessment is vital in balance function evaluation. In addition, this helps to demonstrate that an improved balance ability results from the interventions performed in the clinical setting ${ }^{3,4)}$. Several clinical balance assessments have been developed and used; however, few of balance tools for children exist ${ }^{3}$.

The Pediatric Balance Scale (PBS), modified by based on Berg Balance Scale (BBS) has been used in several studies to assess balance ability in children, especially those with balance problem ${ }^{4,5)}$. However, it is suitable for assessing balance ability in a group of lower-functioning children ages $\leq 6$ because of its propensity to display ceiling effects ${ }^{6}$. To assess balance function in a group of higher-functioning individuals, the Fullerton Advanced Balance (FAB) scale is recommended ${ }^{7)}$. Although the FAB is more suitable for higher-functioning individuals compared to the PBS, the study does not report on the item difficulty between the PBS and the FAB in children with CP. The purpose of this study is to compare the level of difficulty of the PBS with that of the FAB scale in children with CP using Rasch analysis.

\footnotetext{
*Corresponding author. Gyoung-Mo Kim (E-mail: kgm6240@naver.com)

(C)2016 The Society of Physical Therapy Science. Published by IPEC Inc.

This is an open-access article distributed under the terms of the Creative Commons Attribution Non-Commercial No Derivatives (by-nc-nd) License $<$ http://creativecommons.org/licenses/by-nc-nd/4.0/>.
} 
Table 1. Demographic characteristics of the participants (mean \pm SD)

\begin{tabular}{lrcr}
\hline Parameters & Male $(\mathrm{n}=17)$ & Female $(\mathrm{n}=23)$ & Total $(\mathrm{n}=40)$ \\
\hline Age (yrs) & $12.4 \pm 2.7$ & $10.6 \pm 3.1$ & $11.4 \pm 3.1$ \\
Hemiplegia (\%) & $9(52.9)$ & $12(52.2)$ & $21(52.5)$ \\
Diplegia (\%) & $8(47.1)$ & $11(47.8)$ & $19(47.5)$ \\
PBS score & $45.5 \pm 6.4$ & $44.9 \pm 9.3$ & $45.2 \pm 8.1$ \\
FAB score & $23.9 \pm 7.6$ & $22.4 \pm 11.4$ & $23.00 \pm 9.9$ \\
\hline
\end{tabular}

PBS: Pediatric Balance Scale; FAB: Fullerton Advanced Balance scale

\section{SUBJECTS AND METHODS}

Forty children with $\mathrm{CP}($ male $=17$, female $=23)$, who received physical therapy as outpatients at a hospital with a level 1 or 2 based on the Gross Motor Function classification System (GMFCS), and who had sufficient cognition to participate in the study by the Mini-Mental State Examination-Korean (MMSE-K) score of 23 or higher, were included. The exclusion criteria were as follows: (1) history of any orthopedic injuries, and other disease or conditions that could influence standing and gait performance within 3 months, (2) any medical intervention affecting balance function before study. Prior to initiation of the study, the principal investigator explained all procedures and safety in detail to the participants. The participants agreed to the publishing of their study data and signed an informed consent form. All participants completed a general characteristics questionnaire with the following information: gender, age, and medical history. Thereafter, the balance function of each subject was assessed using the PBS and FAB. The order of assessment was randomized using the random number generator in Excel. The assessment was administered by trained one examiner who had experience completing these tests in patients with CP. The subjects were asked to rest to minimize the effect of the previous measurement. Participant instructions were given according to the standardized each test protocol.

The PBS and FAB scale data obtained were analyzed using Rasch analysis with Winstep version 3.71.0 (Linacare, Chicago, IL, USA). Rasch analysis is based on the probability that the response patterns of individuals to the total sample to measure person ability and item difficulty ${ }^{8}$. It converts ordinal-scale values to interval-scale values, which are calibrated on a single linear measurement continuum divided into equal intervals, or logits, for each item. Therefore, Rasch analysis has an advantage that it's focus on the hierarchy of items, i.e., from easy to difficulty to perform in each domain ${ }^{9}$. Based on these results, item difficulty was compared and analyzed after combining the two assessment tools using logit values. This study was approved by the Kyungdong University Human Studies Committees.

\section{RESULTS}

The general characteristics of the participants are presented in Table 1. Among the 24 items of combined PBS and FAB, the most difficult item was "Walk with head turns" (FAB item 6); the easiest item was "Sitting with back unsupported and feet supported on the floor" (PBS item 5). Table 2 shows the items of the combined PBS and FAB, arranged by order of difficulty.

\section{DISCUSSION}

The purpose of this study is to compare the item difficulty between the PBS and FAB scales using Rasch analysis, which has recently been widely used for the evaluation of the construction and validation of functional assessment tools in various fields. Item difficulty is expressed by logit value in Rasch analysis, with a higher value indicating a high item difficulty level ${ }^{8,9)}$. The PBS and FAB scales were combined to compare the relative item difficulty. The results show that among the 24 items of the combined PBS and FAB scale, the most difficult item was "Walk with head turns", and the easiest item was "Sitting with back unsupported and feet supported on the floor".

Item difficulty estimates are presented in logits, where a logit value of 0 is the average of the item difficulty measures ${ }^{10)}$. In this study, the "Turning to look behind left and right shoulders while standing still" item of the FAB is of approximately average difficulty. The items with higher positive logit values are most difficult than those with lower positive or negative logit values. Of the 14 PBS items, five items (item 8, 9, 10,13, and 14) presented positive logit values, and nine items (item $1,2,3,4,5,6,7,11$, and 12) negative logit values. These findings are consistent with previous research and similar to developmental skill acquisitions in children ${ }^{3}$. In addition, of the 10 FAB scale items, only one (item 1) showed a negative logit value, and the rest showed positive logit values. Therefore, PBS has relatively easier items than the FBA scale. The lack of items assessing higher function is the primary weakness of the PBS; thus, the assessment of higher-functioning individuals is limited ${ }^{3)}$. Furthermore, the PBS is not enough to distinguish the difference of function in children with cerebral palsy ${ }^{11)}$.

In conclusion, the FAB scale is a more appropriate tool for assessing balance ability in a group of higher-functioning individuals than the PBS. This study has several limitations. First, the participants were not selected from a representative population, and data were obtained only one hospital; thus, the generalization of our results is limited. Second, other psycho- 
Table 2. Item difficulty of the combined PBS and FAB

\begin{tabular}{llll}
\hline No & Item & Logit & Error \\
\hline FAB 9 & Walk with head turns & 2.82 & 0.2 \\
FAB 6 & Stand on one leg & 2.39 & 0.18 \\
FAB 5 & Tandem walk & 2.19 & 0.18 \\
PBS 9 & Standing on one foot & 1.93 & 0.18 \\
PBS 8 & Standing with one foot in front & 1.87 & 0.18 \\
FAB 7 & Stand on foam, eyes closed & 1.08 & 0.18 \\
FAB 2 & Reaching forward to an object & 0.88 & 0.18 \\
FAB 4 & Step up and over & 0.88 & 0.18 \\
FAB 10 & Reactive postural control & 0.88 & 0.18 \\
PBS 13 & Placing alternate foot on step stool while standing unsupported & 0.74 & 0.19 \\
PBS 14 & Reaching forward with outstretched arm while standing & 0.52 & 0.19 \\
FAB 8 & Tow-footed jump & 0.33 & 0.2 \\
PBS 10 & Turning 360 degrees & 0.21 & 0.2 \\
FAB 3 & Turn in full circle & 0.21 & 0.2 \\
PBS 11 & Turning to look behind left and right shoulders while standing still & -0.09 & 0.21 \\
FAB 1 & Standing with feet together and eyes closed & -0.33 & 0.23 \\
PBS 7 & Standing unsupported with feet together & -0.55 & 0.24 \\
PBS 12 & Pick up object from the floor from a standing position & -1.37 & 0.3 \\
PBS 1 & Sitting to standing & -1.9 & 0.36 \\
PBS 3 & Transfers & -1.9 & 0.36 \\
PBS 6 & Standing unsupported with eyes closed & -1.9 & 0.36 \\
PBS 4 & Standing unsupported & -2.04 & 0.38 \\
PBS 2 & Standing to sitting & -2.89 & 0.57 \\
PBS 5 & Sitting with back unsupported and feet supported on the floor & -3.97 & 1 \\
& Mean & 0 & 0.28 \\
\hline
\end{tabular}

metric properties, such as, age, cognition, fear of falling, and CP classification that may affect balance function in children with CP were not considered. Further study is required for incorporate data of children with CP in various regions, and other psychometric properties affecting balance function should be considered.

\section{REFERENCES}

1) Rosenbaum PL, Walter SD, Hanna SE, et al.: Prognosis for gross motor function in cerebral palsy: creation of motor development curves. JAMA, 2002, 288: 1357-1363. [Medline] [CrossRef]

2) Shumway-Cook A, Hutchinson S, Kartin D, et al.: Effect of balance training on recovery of stability in children with cerebral palsy. Dev Med Child Neurol, 2003, 45: 591-602. [Medline] [CrossRef]

3) Darr N, Franjoine MR, Campbell SK, et al.: Psychometric properties of the pediatric balance scale using rasch analysis. Pediatr Phys Ther, 2015 , 27: 337-348. [Medline] [CrossRef]

4) Verbecque E, Lobo Da Costa PH, Vereeck L, et al.: Psychometric properties of functional balance tests in children: a literature review. Dev Med Child Neurol, 2015, 57: 521-529. [Medline] [CrossRef]

5) Franjoine MR, Gunther JS, Taylor MJ: Pediatric balance scale: a modified version of the berg balance scale for the school-age child with mild to moderate motor impairment. Pediatr Phys Ther, 2003, 15: 114-128. [Medline] [CrossRef]

6) Franjoine MR, Darr N, Held SL, et al.: The performance of children developing typically on the pediatric balance scale. Pediatr Phys Ther, 2010, 22: $350-359$. [Medline] [CrossRef]

7) Rose DJ, Lucchese N, Wiersma LD: Development of a multidimensional balance scale for use with functionally independent older adults. Arch Phys Med Rehabil, 2006, 87: 1478-1485. [Medline] [CrossRef]

8) Klein PJ, Fiedler RC, Rose DJ: Rasch analysis of the Fullerton Advanced Balance (FAB) scale. Physiother Can, 2011, 63: 115-125. [Medline] [CrossRef]

9) Duncan PW, Bode RK, Min Lai S, et al. Glycine Antagonist in Neuroprotection Americans Investigators: Rasch analysis of a new stroke-specific outcome scale: the Stroke Impact Scale. Arch Phys Med Rehabil, 2003, 84: 950-963. [Medline] [CrossRef]

10) Bond TG, Fox CM: Applying the Rasch Model: fundamental measurement in the human sciences, 2nd ed. New Jersey: Lawrence Erlbaum Associates, 2007, pp 37-43.

11) Duarte NA, Grecco LA, Franco RC, et al.: Correlation between Pediatric Balance Scale and Functional Test in children with cerebral palsy. J Phys Ther Sci, 2014, 26: 849-853. [Medline] [CrossRef] 